\title{
Minnesota Nurses' Study: Perceptions of Violence and the Work Environment
}

\author{
Nancy M. NACHREINER*, Susan G. GERBERICH, Andrew D. RYAN \\ and Patricia M. McGOVERN
}

University of Minnesota, Minneapolis, Minnesota, USA

Received May 21, 2007 and accepted July 10, 2007

\begin{abstract}
Work-related violence is an important problem worldwide, and nurses are at increased risk. This study identified rates of violence against nurses in Minnesota, USA, and their perceptions of the work environment. A sample of 6,300 randomly selected nurses described their experience with work-related violence in the previous year. Differences in perceptions of the work environment and work culture were assessed, based on a nested case-control study, comparing nurses who experienced assault to non-assaulted nurses. Annual rates of physical and non-physical assault, per 100 nurses, were 13.2 (95\% CI: 12.2-14.3), and 38.8 (95\% CI: 37.4-40.4). Cases were more likely than controls to report: higher levels of work stress; that assault was an expected part of the job; witnessing all types of patient-perpetrated violence in the previous month; and taking corrective measures against work-related assault. Controls versus cases were more likely to perceive higher levels of morale, respect and trust among personnel, and that administrators took action against assault. Nurses frequently experienced work-related violence, and perceptions of the work environment differed between nurses who had experienced physical assault, and those who had not. Employee safety, morale, and retention are particularly important in light of the nursing shortage, and knowledge of nurses' perceptions will assist in tailoring interventions aimed at reducing the substantial risk of physical assault in health care settings.
\end{abstract}

Key words: Physical assault, Non-physical violence, Work-related violence, Nurses, Occupational

\section{Introduction}

Work-related violence was not apparently identified as an important public health problem in the United States until $1991^{1)}$. In the United States, homicide was the fourth leading cause of occupational fatality in $2005^{2}$, and approximately 1.7 million non-fatal acts of work-related violence occurred annually in the United States between 1993 and 1999³). However, work-related violence is not contained within national borders. Chappell and Di Martino ${ }^{4)}$ document international studies of work-related violence occurring in: Australia, Brazil, Bulgaria, France, Germany, Japan, Lebanon, Portugal, South Africa, Spain, Thailand, the United Kingdom, and the United States. In addition, many studies on work-

\footnotetext{
*To whom correspondence should be addressed.
}

related violence also exist outside the previously mentioned locations, including: Canada $^{5)}$; Sweden ${ }^{6}$; Nigeria ${ }^{7}$; Jamaica $^{8}$; Taiwan ${ }^{9)}$; Ireland $^{10)}$; and Turkey ${ }^{11}$. Specific industries or groups of workers appear to be at increased risk for violence. Hospital and health care workers, particularly nurses, are at high risk for non-fatal violence ${ }^{12-14)}$. Between 1993 and 1999 in the United States, nurses experienced work-related violence at the highest rate (22 per 1000 workers) among all types of health care workers ${ }^{3)}$. The purpose of this study was to identify the perceptions of violence and the work environment among nurses in Minnesota, USA.

\section{Subjects and Methods}

\section{Study population}

The target population for this study was all Registered 
Nurses (RNs) (57,388) and Licensed Practical Nurses (LPNs) $(21,740)$ licensed in the state as of October 1, 1998 ${ }^{15}$. Eligible participants worked in Minnesota, USA during the 12 months prior to the date they completed the survey. A sample of 220 nurses was selected for pilot testing, and 6,300 nurses were randomly sampled for the full study. Approval to conduct the study was provided by the University of Minnesota Institutional Review Board.

\section{Definitions}

Consistent with the definition used by the U.S. National Institute for Occupational Safety and Health ${ }^{16)}$, physical assault was defined as being hit, slapped, kicked, pushed, choked, grabbed, sexually assaulted, or otherwise subjected to physical contact intended to injure or harm. Non-physical violence included threats, sexual harassment, and verbal abuse. Violence was considered to be work-related if it occurred in the work environment or during any activities associated with the job. This included work-related travel.

\section{Selection of cases and controls}

After completion of the pilot study, 6,300 nurses were mailed the Phase 1 questionnaire to establish employment status and the incidence and consequences of work-related violence. Based on the $78 \%$ response from Phase 1, 475 cases (working nurses who reported at least one event of physical assault during the previous 12 months) and 1,425 controls (working nurses who did not experience physical assault) were included in Phase 2 to identify risk and protective factors for work-related physical assault. Factors assessed included various characteristics of the nurse (age, gender, years worked in that department, etc.); the perpetrators (impairment status, gender, etc.); and the work environment (type of facility, department, environmental characteristics-lighting, accessible exits, etc.). The descriptive factors included in this manuscript are based on the nurses' perceptions of expectations of violence, corrective measures taken against violence, and the witnessing of patient-perpetrated violence.

\section{Data collection}

For both the Phase 1 survey and the Phase 2 case-control study, a maximum of four follow-up mailings were sent. The initial mailing and first three follow-up mailings included full surveys; the fourth follow-up mailing contained a condensed, one-page survey. These mailings included a cover letter providing informed consent, the survey instrument, and a postage-paid return envelope.

\section{Analyses}

Rates of violence were calculated based on data from the Phase 1 study, including both physical and non-physical violence. Descriptive factors of cases and controls are restricted to physical assault perpetrated by patients, which accounted for approximately $96 \%$ of cases $(n=310)$. Descriptive analyses were performed using SAS (version 8.2).

\section{Limitations}

A potential limitation of this study is that nurses selfreported information on their written surveys. An attempt to minimize recall bias was made by limiting reporting to events which occurred in the previous year, in the first phase of the study, and limiting recall to one specific month in the past year, for the second phase of this study. This method has been used successfully in previous studies ${ }^{10,17)}$. Nurses were contacted to clarify missing or unclear information in an attempt to minimize information bias. Additionally, the associations reported were the results of bivariate tests and, thus, are preliminary findings that suggest a need for subsequent multivariate estimations.

\section{Results}

\section{Phase 1}

Based on the Phase 1 survey, the majority of respondents were women (96\%), RNs (75\%), and the average age was $46 \mathrm{yr}( \pm \mathrm{SD}, 10.1)$. The annual physical assault rate was 13.2 per 100 nurses (95\% CI 12.2-14.3); the non-physical violence rate was 38.8 (95\% CI; 37.4-40.4) $)^{18)}$.

\section{Phase 2}

Response for the Phase 2 (case-control) study was $67 \%$. The majority of respondents were female RNs, age 40 to 49. Most cases worked in nursing homes or long term care facilities, while controls worked in hospital in-patient facilities ${ }^{19}$. Cases also most frequently worked in long-term care departments within these facilities, with a geriatric population, compared to controls who worked in medical/ surgical departments with an adult (non-geriatric) population ${ }^{19}$. Cases and controls described their perceived work environment (See Table 1). Both groups described high levels of work stress (77\% and 63\% respectively); however, the majority of nurses also reported positive levels of "respect and trust among personnel" (75\% and 83\% respectively). Despite high levels of trust among personnel, $59 \%$ of cases and $46 \%$ of controls reported the overall quality of morale as poor or fair. The majority of nurses rated supervisor support (prior to the assault for cases, and a 
Table 1. Work environment perceptions

\begin{tabular}{|c|c|c|c|}
\hline & $\begin{array}{c}\% \\
\text { Cases } \\
(n=310)\end{array}$ & $\begin{array}{c}\% \\
\text { Controls } \\
(n=946)\end{array}$ & $\begin{array}{c}\chi^{2} \\
p \text { value }\end{array}$ \\
\hline \multicolumn{4}{|l|}{ Work Stress } \\
\hline No or some stress & 21 & 36 & $<0.01$ \\
\hline Moderate or a lot of stress & 77 & 63 & \\
\hline \multicolumn{4}{|l|}{ Quality of respect/trust among personnel } \\
\hline Poor or Fair & 24 & 17 & 0.03 \\
\hline Good, Very good or Outstanding & 75 & 83 & \\
\hline \multicolumn{4}{|l|}{ Quality of morale among personnel } \\
\hline Poor or Fair & 59 & 46 & $<0.01$ \\
\hline Good, Very good or Outstanding & 40 & 53 & \\
\hline \multicolumn{4}{|c|}{ Supervisor showed concern for those supervised } \\
\hline Disagree or Strongly disagree & 25 & 21 & 0.17 \\
\hline Agree or Strongly agree & 68 & 73 & \\
\hline \multicolumn{4}{|l|}{ Supervisor paid attention to what I said } \\
\hline Disagree or Strongly disagree & 24 & 20 & 0.04 \\
\hline Agree or Strongly agree & 70 & 75 & \\
\hline \multicolumn{4}{|l|}{$\begin{array}{l}\text { Administration expected assault as a possible } \\
\text { consequence of the job }\end{array}$} \\
\hline Disagree or Strongly disagree & 32 & 57 & $<0.01$ \\
\hline Agree or Strongly agree & 61 & 34 & \\
\hline \multicolumn{4}{|l|}{$\begin{array}{l}\text { Administration took corrective/preventive } \\
\text { measures against workplace assault }\end{array}$} \\
\hline Disagree or Strongly disagree & 41 & 27 & $<0.01$ \\
\hline Agree or Strongly agree & 46 & 60 & \\
\hline \multicolumn{4}{|l|}{$\begin{array}{l}\text { Coworkers expected assault as a possible } \\
\text { consequence of the job }\end{array}$} \\
\hline Disagree or Strongly disagree & 20 & 54 & $<0.01$ \\
\hline Agree or Strongly agree & 76 & 39 & \\
\hline \multicolumn{4}{|c|}{$\begin{array}{l}\text { Coworkers took corrective/preventive measures } \\
\text { against workplace assault }\end{array}$} \\
\hline Disagree or Strongly disagree & 20 & 28 & $<0.01$ \\
\hline Agree or Strongly agree & 71 & 58 & \\
\hline \multicolumn{4}{|l|}{$\begin{array}{l}\text { I expected assault as a possible consequence } \\
\text { of the job }\end{array}$} \\
\hline Disagree or Strongly disagree & 21 & 55 & $<0.01$ \\
\hline Agree or Strongly agree & 77 & 42 & \\
\hline \multicolumn{4}{|l|}{$\begin{array}{l}\text { I took corrective/preventive measures against } \\
\text { workplace assault }\end{array}$} \\
\hline Disagree or Strongly disagree & 16 & 24 & $<0.01$ \\
\hline Agree or Strongly agree & 81 & 67 & \\
\hline \multicolumn{4}{|l|}{$\begin{array}{l}\text { Frequency witnessing patients perpetrating } \\
\text { physical assault in previous month }\end{array}$} \\
\hline Never & 13 & 63 & $<0.01$ \\
\hline 1 to 3 times & 44 & 27 & \\
\hline 4 to 10 times & 20 & 5 & \\
\hline More than 10 times & 23 & 4 & \\
\hline \multicolumn{4}{|l|}{$\begin{array}{l}\text { Frequency witnessing patients perpetrating } \\
\text { threats in previous month }\end{array}$} \\
\hline Never & 19 & 55 & $<0.01$ \\
\hline 1 to 3 times & 32 & 30 & \\
\hline 4 to 10 times & 24 & 8 & \\
\hline More than 10 times & 24 & 5 & \\
\hline \multicolumn{4}{|l|}{$\begin{array}{l}\text { Frequency witnessing patients perpetrating } \\
\text { sexual harassment in previous month }\end{array}$} \\
\hline Never & 52 & 78 & $<0.01$ \\
\hline 1 to 3 times & 29 & 17 & \\
\hline 4 to 10 times & 8 & 3 & \\
\hline More than 10 times & 10 & 2 & \\
\hline \multicolumn{4}{|l|}{$\begin{array}{l}\text { Frequency witnessing patients perpetrating } \\
\text { verbal abuse in previous month }\end{array}$} \\
\hline Never & 5 & 33 & $<0.01$ \\
\hline 1 to 3 times & 26 & 39 & \\
\hline 4 to 10 times & 23 & 15 & \\
\hline More than 10 times & 45 & 14 & \\
\hline
\end{tabular}


randomly selected month for controls) in a positive manner. Of cases, $68 \%$ agreed or strongly agreed their supervisor showed concern for those he/she supervised; the corresponding percentage for controls was $73 \%$. Additionally, most nurses felt supervisors paid attention to those they supervised (cases: 70\%, controls: $75 \%$ ).

Nurses were asked about whether assault was expected as a consequence of the job, and whether corrective measures were taken against workplace assault. Perceptions of these characteristics were assessed on three levels: 1 ) self-ratings by the nurses; 2) the nurses' perceptions of administration; and 3) the nurses' perceptions of co-workers. Cases more frequently than controls perceived that expectations of experiencing assault on the job existed at all levelsadministrative, coworker, and personal. Approximately 77\% of cases agreed or strongly agreed that they expected assault as a possible consequence of the job, compared to $42 \%$ of controls. When asked whether corrective or preventive measures were taken against possible work-related assault, the cases perceived they and their coworkers took action more frequently than the controls; $81 \%$ of cases reported taking action, compared to $67 \%$ of controls. In contrast, controls were more likely than cases to perceive that their administrators took preventive or corrective action against assaults (cases 46\%, controls 60\%) (Fig. 1).

For all types of violence (physical assault, threat, sexual harassment, and verbal abuse), cases reported higher frequencies of witnessing patient-perpetrated violence in the past month, with verbal abuse being the most frequently witnessed type of violence.

\section{Discussion}

Rates of violence are a concern for this population of Minnesota nurses, with over 13 per 100 nurses reporting at least one episode of physical assault in the past year, and at least 38 per 100 nurses reporting at least one episode of threat, sexual harassment or verbal abuse. The importance of this finding confirms some previous reports with high levels of violence ${ }^{12-14}$. In 2000, a joint group including the International Labour Office (ILO), the International Council of Nurses (ICN), the World Health Organization (WHO), and Public Services International (PSI) commissioned several country-wide studies of work-related violence in the health care sector ${ }^{20)}$. Although study methods and definitions differed from the current study, it is interesting to compare the Di Martino results to the findings in the current paper (See Table 2).

Nurses, both cases and controls, perceived a high level
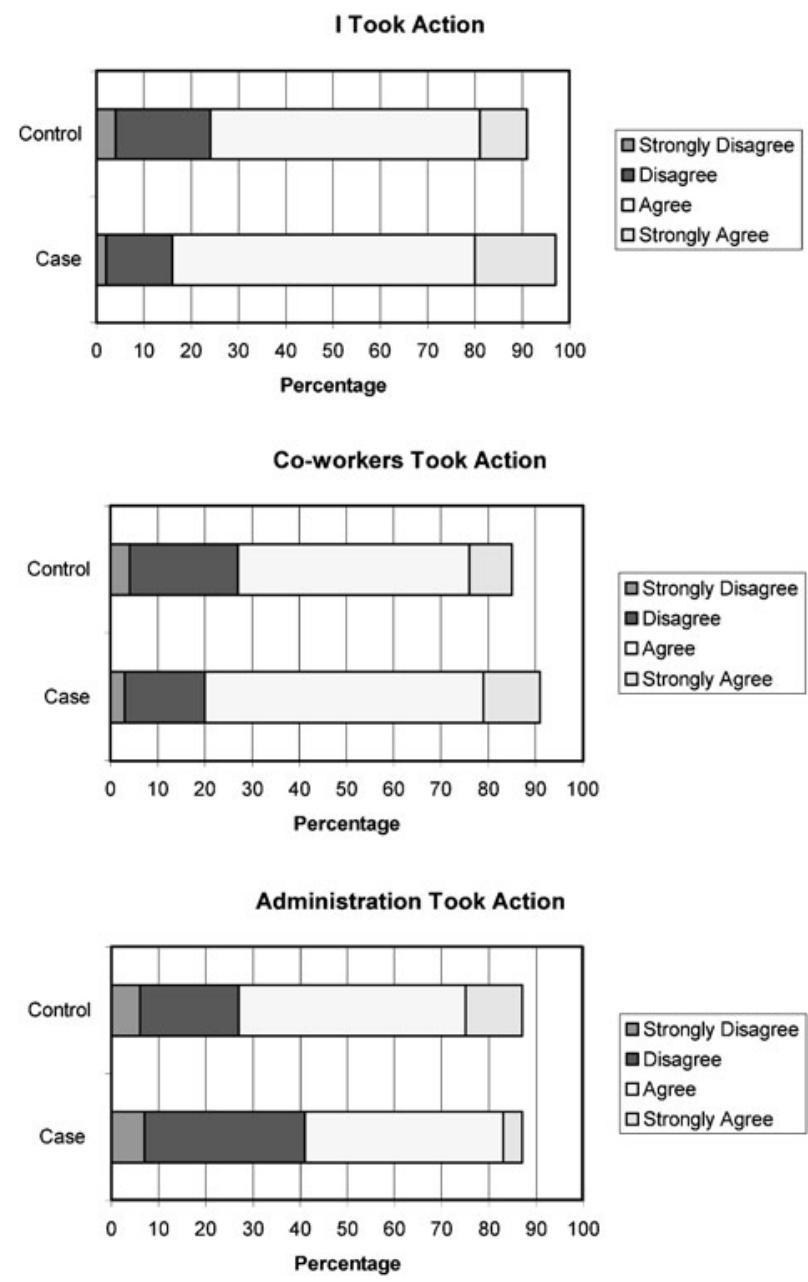

Fig. 1. Perceptions of preventive/corrective actions taken by self, co-workers and administration.

of work-related stress. Both groups ranked the quality of respect and trust among personnel as good, very good, or outstanding, and also ranked supervisor support highly, but, in contrast, felt that the morale among personnel was poor or fair. Di Martino ${ }^{20,21)}$ reported (p. 26), "When stress and violence interact in the workplace as they often do, their negative effects cumulate rapidly and activate a vicious circle which is very difficult to unravel." In comparison, in an online survey of Registered Nurses (RNs), Ulrich et al. ${ }^{22)}$ found that $72 \%$ of American RNs reported "Excellent" or "Good" quality of communication among nurses. In addition, these same researchers noted that the quality of collaboration among RNs was reported as "Excellent" or "Good" by $75 \%$ of nurses. Ulich et al. ${ }^{22)}$, noted that little research specifically addresses how nurses define "respect" and what behaviors are associated with "respect." However, the current findings suggest that while peer relationships are positive, nursing 
Table 2. Health care workers reporting violence in the previous year ${ }^{20)}$

\begin{tabular}{lcc}
\hline Country & Physical assault in past year & Psychological violence in past year \\
\hline Thailand & $10.5 \%$ & $47.7 \%$ \\
South Africa & $9.0 \%$ (private sector) & $60.1 \%$ (public sector) \\
& $17.0 \%$ (public sector) & \\
Bulgaria & $7.5 \%$ & $32.2 \%$ \\
Brazil & $6.4 \%$ & $39.5 \%$ \\
Lebanon & $5.8 \%$ & $40.9 \%$ \\
Portugal & $3.0 \%$ & $51 \%$ (health centre complex) \\
& & $27.4 \%$ (hospital) \\
Australia & (not available) & $67 \%$ \\
\hline
\end{tabular}

morale, which may include feelings of confidence and enthusiasm about one's job or employer, may suffer in association with work-related assault.

Di Martino ${ }^{21)}$ noted that the general culture of the work environment must be taken into consideration when assessing the risk of work-related violence. He noted that a participatory working environment, with open dialogue and communication may defuse the risk of violence. Callaghan ${ }^{23)}$, in a qualitative study of nurses in Scotland, reported very low morale, based primarily on issues of low pay, lack of support for education, limited opportunity for promotion, and job insecurity. Di Martino ${ }^{21)}$ (p. 23) noted that job security is, "always associated with stress and the risk of violence at work." Supervisor support may decrease the amount of stress and violence in the workplace. Findorff et al. ${ }^{24)}$ noted that increased supervisor support decreased the odds of physical and non-physical violence against nurses. Hansen et al. ${ }^{25)}$ also found that bullied employees had lower social support from coworkers and supervisors. Multivariate tests of the association between stress and violence are needed to confirm or reject the effect on morale, given the current nursing shortage and the importance of nursing morale to job retention.

Nurses' perceptions regarding expectations of violence identified important trends in this study. Many nurses agreed or strongly agreed that violence was an expected part of their job. These perceptions are consistent with opinions from other researchers. For example, Trossman ${ }^{26)}$ quoted Kingma, a consultant for the International Council of Nurses (p. 6), "Nurses are expected to deal with conflicts, so if they are harmed by a patient, they feel it reflects badly on their performance". Nurses may not wish to admit to experiencing violence, as they may feel that the situation occurred through some fault of their own. As McPhaul and Lipscomb ${ }^{27)}$ (p. 1) described: work-related violence is a complex problem, partly because of "a health care culture resistant to the notion that health care providers are at risk for patient-related violence, combined with the complacency that violence, if it exists, is a part of the job". Cases more often than controls reported they expected assault as a possible consequence of the job. They also were more likely to perceive that coworkers and administration shared this expectation. It is likely that nurses' belief that violence is an expected consequence of the job may result in underreporting of violence in other studies ${ }^{24}$ and may contribute to a diminishment of the scope of the problem by health care administrators.

When comparing perceptions that corrective or preventive steps had been taken against physical assault, controls were more likely than cases to perceive administration was taking action; however, cases were more likely than controls to perceive that they personally made changes or that their coworkers made changes to correct or prevent work-related assault. It may be that assaulted nurses personally feel they must take action to prevent future violence, while nonassaulted nurses may perceive they do not need to institute protective measures on their own, because they are confident administration is working on their behalf to protect them. Alternatively, it may be that institutions whose top administrators are known by staff to take preventive or corrective action against assaults subsequently experience relatively fewer work-related assaults. Multivariate tests of this association are needed to test this association as nurses' perceptions of their administrators' responsiveness to workrelated violence has implications for employee safety and morale as described above. Chapman and Styles ${ }^{28)}$ noted that it is essential that nurses, government, and the community refuse to accept that violence and aggression are 'just part of the job.'

Cases were also more likely than controls to report witnessing a higher level of violent behavior being perpetrated by patients in the work environment. This 
included all types of violence-physical and non-physical. This is especially important, given that work-related violence has been cited as one reason nurses choose to leave the profession, and because a significant nursing shortage in the United States is expected by $2020^{29}$. Ulrich et al. ${ }^{22)}$ noted that $20 \%$ of American nurses plan to leave their current position in the next 12 months, and over $28 \%$ indicated planning to leave their position within the next three years. It is important to further understand the role of work-related violence as it relates to nurses choosing to leave the profession, so that interventions can be tailored to decrease these risks, and to encourage retention, of nurses.

\section{Conclusion}

Work-related violence appears to be an important problem for Minnesota nurses. Although nurses perceived a high level of quality of respect and trust among personnel, they reported high levels of work-related stress, witnessing of patient-perpetrated violence, and high expectations of assault as a consequence of the job within their environments. This knowledge of nurses' perceptions will assist in tailoring interventions aimed at reducing the substantial risk of physical assault in health care settings.

\section{Acknowledgements}

Support for this effort was provided, in part, by the: National Institute for Occupational Safety and Health, Centers for Disease Control and Prevention, Department of Health and Human Services (R01 OH03438); the Regional Injury Prevention Research Center and the Center for Violence Prevention and Control, Division of Environmental Health Sciences, School of Public Health, University of Minnesota, Minneapolis, Minnesota. Collaborating organizations included the: Minnesota Hospital and Health Care Partnership; Minnesota Nurses' Association; and Minnesota Licensed Practical Nurses' Association.

\section{References}

1) Rosenberg M, Fenley M (1991) Violence in America: A Public Health Approach, Oxford University Press, New York.

2) U.S. Department of Labor. Bureau of Labor Statistics. National Census of Fatal Occupational Injuries in 2005, USDL 06-1364. http://stats.bls.gov/news.release/pdf/cfoi.pdf. Accessed March 20, 2007.

3) Duhart DT (2001) Violence in the workplace, 1993-1999. National Crime Victimization Survey, Bureau of Justice Statistics Special Report, U.S. Department of Justice, Office of Justice Programs, Washington, DC.

4) Chappell D, Di Martino V (2006) Violence at Work, 3rd Ed., International Labour Office, Geneva.

5) Hekseth KL, Duncan SM, Estabrooks CA, Reimer MA, Giovannetti P, Hyndman K, Acorn S (2003) Workplace violence in Alberta and British Columbia hospitals. Health Policy 63, 311-21.

6) Menckel E, Viitasara E (2002) Threats and violence in Swedish care and welfare-magnitude of the problem and impact on municipal personnel. Scand J Caring Sci 16, 37685.

7) Orji EO, Fasubba OB, Onwudiegwu U, Dare FO, Ogunniyi SO (2002) Occupational health hazards among health care workers in an obstetrics and gynaecology unit of a Nigerian teaching hospital. J Obstet Gynaecol 22, 75-8.

8) Jackson M, Ashley D (2005) Physical and psychological violence in Jamaica's health sector. Rev Panam Salud Publica 18, 114-21.

9) Lin Y, Liu H (2005) The impact of workplace violence on nurses in South Taiwan. Int J Nurs Stud 42, 773-8.

10) Ryan D, Maguire J (2006) Aggression and violence- a problem in Irish Accident and Emergency departments? J Nurs Mgmt 14, 106-15.

11) Oztunc G (2006) Examination of incidents of workplace verbal abuse against nurses. J Nurs Care Qual 4, 360-5.

12) Peek-Asa C, Howard J, Vargas L, Krauss JF (1997) Incidence of nonfatal workplace assault injuries determined from employer's reports in California. J Occup Environ Med 39, 44-50.

13) National Institute for Occupational Safety and Health (NIOSH) (2002) Violence: Occupational Hazards in Hospitals, U.S. Department of Health and Human Services, Public Health Service, Centers for Disease Control and Prevention, DHHS (NIOSH), Publication No.2002-101, NIOSH, Washington, DC.

14) Arnetz JE, Arnetz BB, Soderman E (1998) Violence toward health care workers: prevalence and incidence at a large regional hospital in Sweden. AAOHN J 46, 107-14.

15) State of Minnesota Mailing List Service (1998) St. Paul, Minnesota.

16) National Institute for Occupational Safety and Health (NIOSH) (1996) Current Intelligence Bulletin 57, Violence in the Workplace: Risk Factors and Prevention Strategies, U.S. Department of Health and Human Services, Public Health Service, Centers for Disease Control and Prevention, DHHS (NIOSH) Publication; No.96-100, NIOSH, Washington, DC.

17) Lee SS, Gerberich SG, Waller LA, Anderson A, McGovern $\mathrm{P}$ (1999) A case-control study of work-related assault injuries among nurses. Epidemiology 10, 685-91.

18) Gerberich SG, Church TR, McGovern PM, Hansen HE, Nachreiner NM, Geisser MS, Ryan AD, Mongin SJ, Watt GD (2004) An epidemiological study of the magnitude and consequences of work-related violence: the Minnesota nurses' study. OEM 61, 495-503. 
19) Gerberich SG, Church TR, McGovern PM, Hansen HE, Nachreiner NM, Geisser MS, Ryan AD, Mongin SJ, Watt GD, Jurek A (2005) Risk factors for work-related assaults on nurses. Epidemiology 16, 704-9.

20) Di Martino V (2002) Workplace violence in the health sector: Country case studies: Brazil, Bulgaria, Lebanon, Portugal, South Africa, Thailand and an additional Australian study. http://www.ilo.org/public/english/dialogue/sector/papers/ health/violence-ccs.pdf. Accessed June 27, 2007.

21) Di Martino V (2003) Workplace violence in the health sector: Relationship between work stress and workplace violence in the health sector. http://www.ilo.org/public/english/ dialogue/sector/papers/health/stress-violence.pdf. Accessed June 27, 2007.

22) Ulrich BT, Lavandero R, Hart KA, Woods D, Leggett J, Taylor D (2006) Critical care nurses' work environments: a baseline status report. Crit Care Nurs 26, 46-57.

23) Callaghan $\mathrm{M}$ (2003) Nursing morale: what is it like and why? J Adv Nurs 42, 82-9.
24) Findorff MJ, McGovern P, Wall M, Gerberich SG, Alexander B (2004) Risk factors for work related violence in a health care organization. Inj Prev 10, 296-302.

25) Hansen AM, Hogh A, Persson R, Karlson B, Garde AH, Orbaek P (2006) Bullying at work, health outcomes and physiological stress response. J Psychosom Res 60, 63-72.

26) Trossman $S$ (2006) Not 'part of the job': Nurses want to put an end to workplace violence. Am Nurs 1, 6-7.

27) McPhaul KM, Lipscomb JA (2004) Workplace violence in health care: Recognized but not regulated. Online Journal of Issues in Nursing 9, manuscript 6. http://www. nursingworld.org/ojin/topic25/tpc25_6.htm. Accessed March 7, 2007.

28) Chapman R, Styles I (2006) An epidemic of abuse and violence: Nurse on the front line. Accid Emerg Nurs 14, 245-9.

29) Auerbach DA, Buerhaus PI, Staiger DO (2007) Better late than never: workforce supply implications of later entry into nursing. Health Aff 26, 178-85. 